\title{
An Origin of Life on Mars
}

\author{
Christopher P. McKay \\ Space Science Divison, NASA Ames Research Center, Moffett Field, California 94035 \\ Correspondence: chris.mckay@nasa.gov
}

Evidence of past liquid water on the surface of Mars suggests that this world once had habitable conditions and leads to the question of life. If there was life on Mars, it would be interesting to determine if it represented a separate origin from life on Earth. To determine the biochemistry and genetics of life on Mars requires that we have access to an organism or the biological remains of one-possibly preserved in ancient permafrost. A way to determine if organic material found on Mars represents the remains of an alien biological system could be based on the observation that biological systems select certain organic molecules over others that are chemically similar (e.g., chirality in amino acids).

\section{MARS AND A SECOND GENESIS OF LIFE}

$M$ ars today is a cold dry desert world with surface conditions that are not habitable even for the hardiest life forms from Earth. The average surface temperature is $-60^{\circ} \mathrm{C}$ and the atmospheric pressure is near the triple point of water: 120 times lower than sea level pressure on Earth. Even worse for habitability, solar ultraviolet light at wavelengths down to 190 $\mathrm{nm}$ penetrates to the surface. Although there is ample evidence for $\mathrm{H}_{2} \mathrm{O}$ on Mars, there has been no direct observation of liquid water: only ice, vapor, and geomorphological traces of the action of past liquid water.

In spite of the harshness of the present Martian environment, the Red Planet is a prime target for astrobiology. The motivation for the search for life on Mars comes from the evidence of past water activity. Figure 1 shows an image of Nanedi Vallis, which is perhaps the best example of the long-term flow of liquid water on Mars (Malin and Carr 1999). The canyon is about 2 $\mathrm{km}$ across and shows a sinuous pattern consistent with slow erosive fluid flow. The canyon is probably not the actual riverbed. Instead, the bed of the river that carved the canyon is visible in the upper portion of the image. The small size of the riverbed compared to the large canyon indicates that the liquid flowed for a long period of time-although not necessarily continuously. Other fluids suggested as possible geological agents on Mars include wind, glacial ice, lava, and liquefied $\mathrm{CO}_{2}$. Liquid water, flowing repeatedly and stably on the surface, best explains the features seen in Figure 1.

It is useful to more carefully consider what we are searching for on Mars. Until recently, it was assumed that if there ever were life on Mars, it would necessarily represent a second genesis - a different origin from life on Earth. However, it is now known that many of the

Editors: David Deamer and Jack W. Szostak

Additional Perspectives on The Origins of Life available at www.cshperspectives.org

Copyright (C) 2010 Cold Spring Harbor Laboratory Press; all rights reserved; doi: 10.1101/cshperspect.a003509

Cite this article as Cold Spring Harb Perspect Biol 2010;2:a003509 
C.P. McKay

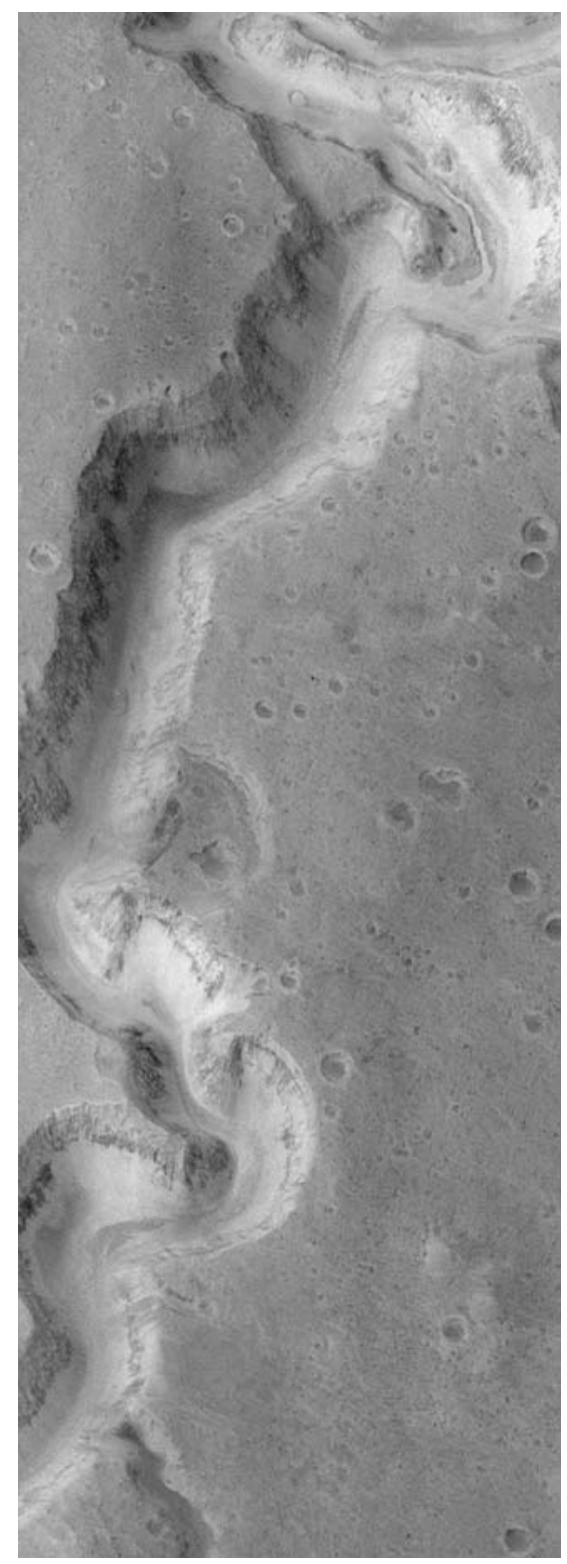

Figure 1. Liquid water on another world. Mars Global Surveyor image showing Nanedi Vallis in the Xanthe Terra region of Mars. Image covers an area $9.8 \mathrm{~km}$ by $18.5 \mathrm{~km}$; the canyon is about $2.5 \mathrm{~km}$ wide. This image is the best evidence we have of liquid water on Mars. Photo from NASA/Malin Space Sciences.

meteorites found on Earth have come from Mars (McSween 1984). Furthermore, studies of the magnetic domains within one of these meteorites by Weiss et al. (2000) have shown that interior temperatures never exceed the survival limits of microorganisms. Thus, it is necessary to consider the possibility that life from Mars was carried to Earth and it is possible that life from Earth could have similarly been carried to Mars-although this path may be less probable. This implies that the discovery of life on Mars does not automatically mean the discovery of a second genesis. To demonstrate a second genesis, it will be necessary to show that Martian life is not related to Earth life.

The search for a second example of life is a key goal for astrobiology. All life on Earth shares common biochemistry and descends from a common ancestor. This prevents us from understanding which aspects of biochemistry and genetics are essential features of life and which are merely particular to the evolutionary history of life on this planet. To develop a more general understanding of life, we need more than one example. Hence, we hope that Mars may have been the site of an independent origin of life.

To determine if life on Mars represents a second type of life requires that we study biological material: Fossils are not enough. Mineralized fossils or tracks of life would be proof of life on Mars, but would not inform us about the relationship of that life to Earth's life. To determine that relationship, we need to study the genetic material and biochemical structure of Martian life-something that can only be done on organisms - alive or dead. We would be convinced of a shared origin of life if Mars had the same chirality, choice of amino acids, genetic code, choice of lipids, and so on. If any or all of these were substantially different, we might conclude a separate origin.

\section{THE ORIGIN OF LIFE: WHAT WE KNOW FROM EARTH THAT APPLIES TO MARS}

Everything we know about biology we have learned by studying the single example of life on Earth. The nature of life and its early history inform our search for life on Mars, and elsewhere in the universe. The earliest firm evidence for life on Earth dates back 3.5 billion years ago and is in the form of fossil microbial mats (Tice and Lowe 2004; Allwood et al. 2006). There are 
also chemical signatures consistent with life in rocks that are 3.8 billion years old (Schidlowski 1988; Abramov and Mojzsis 2009). The appearance of life on Earth was soon after the end of the late heavy bombardment (Abramov and Mojzsis 2009), suggesting that it appeared as soon as conditions on the surface of the Earth became able to support liquid water environments.

Although the early appearance of life on Earth seems certain, how life originated on Earth remains unclear, with multiple hypotheses competing for attention. Nonetheless, all the scenarios suggested for the origin of life on early Earth can be reviewed for their applicability to early Mars. Figure 2 shows a diagram of the published proposals for the origin of life on Earth (Davis and McKay 1996).

The first divide between the proposals for how life first appeared on the Earth is between those postulating that life arose independently on Earth and those that postulate that life was carried to Earth from elsewhere. If life arose on Earth, the next logical division is between an organic and inorganic nature for that early life. Further divisions within the organic origin of life relate to the nature of the energy source and metabolism for the first organism. How can these ideas be applied to a possible origin of life on Mars? First, what all have in common is a requirement for liquid water environmentsthe common thread for life today as well as for its origins. Second, all the scenarios listed in Figure 2 could apply to Mars. This is hardly surprising since our understanding of the environment on early Mars suggests that it had a range of environments similar to those on early Earth. Thus, whatever specific conditions and environments led to life on Earth were probably present on Mars as well.

An interesting contrast between Earth and Mars with respect to the origin of life is that the record of early events may be better preserved on Mars than on Earth. The very processes that maintain the habitability of Earth have virtually destroyed the evidence of the first traces of life. Thus, if present on both Earth and Mars sometime before 3.8 billion years ago, the best place to search for physical evidence of the steps that lead to life may be on Mars.

\section{SEARCHING FOR EVIDENCE OF A SECOND GENESIS OF LIFE ON MARS}

There are several possible places on Mars where we might find evidence of life that can be used to determine if it emerged as a second genesis. Possible targets include: (1) Life in the surface soil, (2) Life in subsurface liquid water,

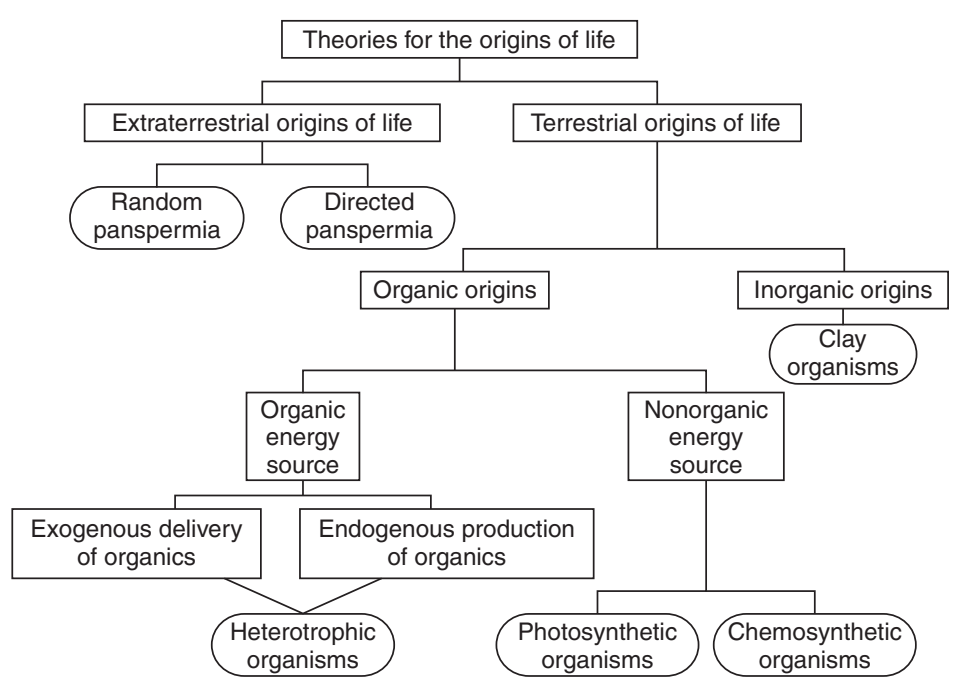

Figure 2. Diagram of the proposed explanations for the origins of life on Earth. Any of these explanations would work on Mars as well as on Earth. From Davis and McKay (1996). 


\section{C.P. McKay}

(3) Organisms, probably dead, but preserved in ancient salt or mineral deposits, and (4) Organisms, dead or alive, preserved in ancient ice. Ancient ice is the most promising target known at this time (Smith and McKay 2005), but before discussing this in more detail, it is interesting to first briefly review the case for the other possibilities.

It is unlikely that the surface soil on Mars, such as sampled by the Viking biology experiments, contain life. The general view of the results of the Viking biology experiment is that there is no life present and the reactivity detected was due to chemical processes (Klein 1999). However, the results of the Labeled Release experiment still invoke speculations that the reactions seen were based on biology (Levin 2007; Levin and Straat 1981). If the surface is inhospitable, many have suggested (Boston et al. 1992) that the subsurface may hold liquid water aquifers that support chemosynthetic life. However, there is as yet no direct evidence of subsurface liquid water. On Earth, the oldest biochemical remains of life are found in ancient amber (Cano and Burucki 1995) and salt deposits (Vreeland et al. 2000). However, in both cases, the antiquity of the life found in these deposits is questioned (Willerslev and Cooper 2005). Although amber - a product of trees-is not expected on Mars, if ancient mineral or salt deposits are found, they should be investigated.

Ancient ice presents a known environment on Mars that may contain the frozen remains of life in an accessible form. Smith and McKay (2005) have suggested that the ancient cratered terrain in the southern highlands of Mars near $80^{\circ} \mathrm{S}, 180^{\circ} \mathrm{W}$ would be an ideal target. The map of Mars (Fig. 3) shows crater distribution, ground ice, and crustal magnetism on Mars. Each green circle represents a crater with a

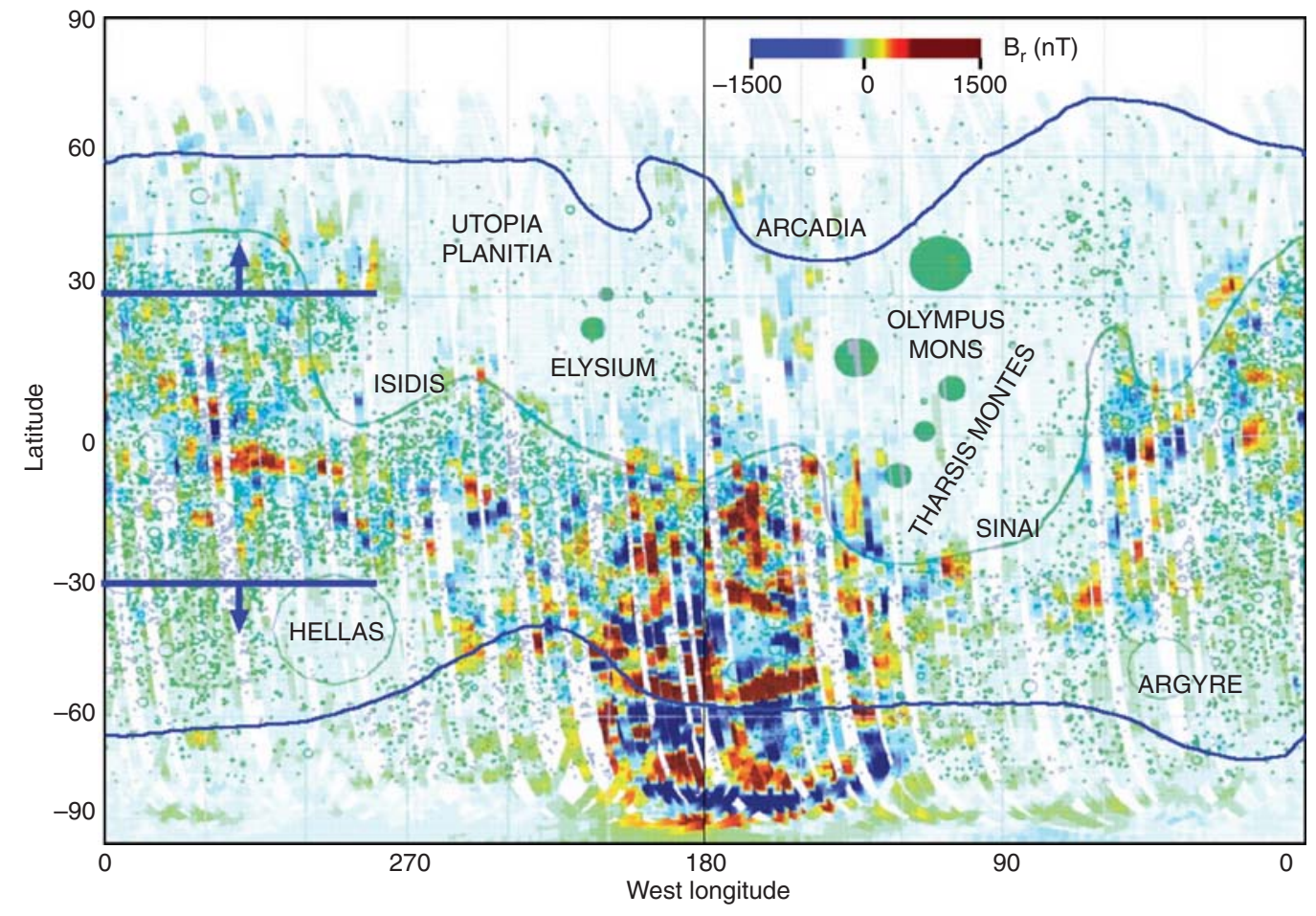

Figure 3. Maps showing crater distribution, ground ice, and crustal magnetism on Mars. The suggested target site for deep drilling to search for evidence of ancient life on Mars is the region between $60^{\circ}$ and $80^{\circ} \mathrm{S}$ at $180^{\circ} \mathrm{W}$, where the ground is heavily cratered, crustal magnetism is preserved, and ground ice is present. Figure from Smith and McKay (2005). 
An Origin of Life on Mars

diameter greater than $15 \mathrm{~km}$ based on the crater distribution in Barlow (1997). The filled green circles are volcanic craters. The boundary between the smooth northern plains and the cratered southern highlands is shown with a green line. The southern regions of Mars are more heavily cratered and therefore considered to be older. The solid blue lines in Figure 4 show the extent of near surface ground ice as determined by the Odyssey mission (Feldman et al. 2002). Ground ice is present near the surface polarward of these lines. Crater morphology indicates deep ground ice poleward of $30^{\circ}$ (Squyres and Carr 1986), shown here by dark blue lines and arrows. Also shown on this figure is the crustal magnetism discovered by Acuña et al. (1999). The crustal magnetism is shown as red for positive and blue for negative. Full scale is $1500 \mathrm{nT}$. The typical strength of Earth's magnetic field at the surface is 50,000 nT. The crustal magnetism is thought to have formed very early in Mars' history, more than 4.5 Gyr ago. The fact of crustal magnetism implies that these surfaces have not been severely heated or shocked. The region between $60^{\circ}$ and $80^{\circ} \mathrm{S}$ at $180^{\circ} \mathrm{W}$ is heavily cratered, preserves crustal magnetism, and has ground ice present. This is the suggested target site for drilling to find the frozen remains of ancient Martian life.

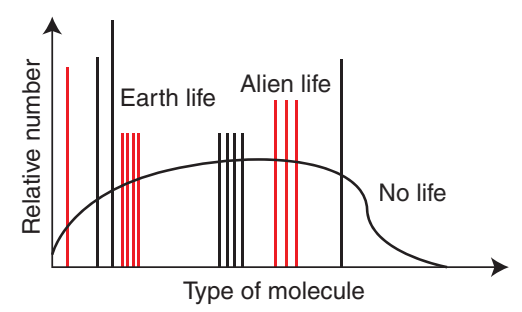

Figure 4. Conceptual comparison of the distribution of molecules in organic matter of biological and nonbiological origin. The ordinate "type of molecule" represents in a general way the size, structure, chirality, and all other features of the molecule. Nonbiological processes produce uniform distributions of organic material, illustrated here by the curve. Biology, in contrast, selects and uses only a few distinct molecules, shown here as spikes (e.g., the 20 L-amino acids on Earth). Alien life might have similar selectivity but based on a different set of molecules (McKay 2004).

\section{DETECTING MARTIAN LIFE}

It may be possible that a mission to Mars, landing in the southern highlands and drilling deeply below the surface, would find organic rich sediments that date back to ancient times when conditions on Mars could have supported widespread life. The challenge then would be to determine if this organic material was of biological origin. We know that there is organic material of nonbiological origin in asteroids, comets, and throughout the outer solar system, so organic material from the deep core on Mars could also be nonbiological.

There are two related questions here: First, is this organic material of biological origin, and second, if it is of biological origin, is it evidence of a second genesis of life? If the organic material pulled from a deep ice core on Mars is derived from biochemistry identical to Earth life, then it should be relatively straightforward to show that it is of biological origin. The technology for direct detection of DNA, RNA, ATP, and other key molecules associated with life on Earth has proceeded to the point that it could easily detect the remains of Earth-like life. These molecules would be preserved over the ages by the low temperatures (Kanavarioti and Mancinelli 1990).

The more difficult, but much more interesting case, is that in which the organic material from Mars is of biological origin but does not have the biomolecules associated with Earth life. In this case, our specialized biochemical tools for detecting life are ineffective.

A possible approach to recognizing alien biology has been suggested by McKay (2004) as the "lego" principle. This is the observation that life, like legos, is based on the repeated use of a small number of building blocks. For legos, the building blocks are small plastic interlocking blocks of a few sizes and shapes. Many different structures can be assembled from these blocks. For life on Earth, the building blocks are the 20 amino acids, the bases A, T, C, G, and $\mathrm{U}$ in DNA and RNA, the sugars, and a few fatty acids (see, e.g., Lehninger 1975, page 27).

The lego principle can form the basis of a search for biological origins due to the contrast 
between the selectivity of biology and the nonselectivity of chemistry. A detailed analysis of organic compounds of nonbiological origin would show that a wide range of organic material is present and that their relative concentrations would be determined by their chemical properties. For organic material of biological origin, the distribution would be a series of spikes. In particular, the concentration of chemically identical molecules might be orders of magnitude different in a biological sample, whereas similar in a chemical sample. An example of this is the biological selection of $\mathrm{L}$ versus $\mathrm{D}$ amino acids for proteins by life on Earth. This concept is presented schematically in Figure 4, which shows the concentration of organic molecules as a function of the type of molecule. The nonbiological distribution is smooth, as seen for example in the Murchison carbonaceous meteorite, whereas the biological distribution is a series of spikes (McKay 2004).

Even if an organism dies, the spiked distribution of organic molecules will persist for some time. However, the chemical distribution in Figure 3 is of higher entropy than the biological distribution, and hence over time, as chemical bonds are broken and reformed, this biological signature will be erased and become indistinguishable from the chemical distribution. Two processes cause this decay: thermal alteration and ionizing radiation. For Mars, the low temperatures in the polar ice ensures that thermal alteration is slow compared to the age of the planet (Kanavarioti and Mancinelli 1990). Ionizing radiation is not temperature dependent. Low but continuous radiation from crustal abundances of $\mathrm{U}$, Th, and K will eventually kill any frozen organism, but will not completely destroy the biological signature of buried frozen organics on Mars (Smith and McKay 2005).

If the organics from Mars show a spiked pattern that is distinct but different from the pattern for Earth life, then this should be both evidence of life and evidence of a second genesis. This is shown schematically in Figure 4 by the red lines. The lego principle thus provides an approach to searching for life that is general enough to detect a second genesis - albeit of carbon-based water-based life. Such life is what we expect to find on Mars and would be a significant first step.

It is not clear how to actually do the measurements illustrated in Figure 4. Currently, the standard approach would be based on GC-MS (gas chromatography-mass spectrometry) with a suitable extraction method. This is, in fact, what was flown to Mars on Viking. However, new methods for organic detection, such as lab-on-a-chip methods, Raman spectroscopy, and UV fluorescence, should also be considered. Analysis of natural soil with low organic content such as the soils of the Atacama Desert (Navarro-Gonzalez et al. 2003, 2006) provide a way to select the most useful methods. Life, or at least its remains, may be out there waiting for us to find it.

It is important to add that even a null result in the search for life on Mars would be informative. It might show that the origin of life is a matter of chance, and the window of opportunity simply was not long enough for life to begin on Mars. Alternatively, it might show that conditions on Mars were too salty, too acid, etc., and inhibited the self-assembly processes required for the origin of life. Finally, we may discover that the origin of life required a fairly specific energy source, mineral, or nutrient (e.g., nitrogen) that was inadequate or absent on Mars. Such insights, even if negative, would help us understand how general the origin of life might be.

The search for life on Mars may be our first chance to discover a second example of life and to investigate the biochemical properties of that life. This possibility is of fundamental importance from both a philosophical and science point of view. Determining where to look and how to search for evidence of a second genesis on Mars is therefore a key task for astrobiology in the next decade.

\section{REFERENCES}

Abramov O, Mojzsis SJ. 2009. Microbial habitability of the terrestrial biosphere during the late heavy bombardment. Nature 459: 419-422.

Acuña MH, Connerney JEP, Ness NF, Lin RP, Mitchell D, Carlson CW, McFadden J, Anderson KA, Reme H, Mazelle C, et al. 1999. Global distribution of crustal 
magnetism discovered by the Mars Global Surveyor MAG/ER experiment. Science 284: 790-793.

Allwood AC, Walter MR, Kamber BS, Burch IW. 2006. Stromatolite reef from the early Archaean era of Australia. Nature 414: 714-718.

Barlow N. 1997. Mars: Impact craters. In Encyclopedia of planetary sciences (ed. JH, Shirley, RW Fairbridge), pp. 196-202. Chapman and Hall, London, UK.

Boston PJ, Ivanov MV, McKay CP. 1992. On the possibility of chemosynthetic ecosystems in subsurface habitats on Mars. Icarus 95: 300-308.

Cano RJ, Burucki MK. 1995. Revival and identification of bacterial spores in 25- to 40-million year old Dominican amber. Science 268: 1060-1064.

Davis WL, McKay CP. 1996. Origins of life: A comparison of theories and application to Mars. Origins Life Evol Biosph 26: $61-73$.

Feldman WC, Boynton WV, Tokar RL, Prettyman TH, Gasnault O, Squyres SW, Elphic RC, Lawrence DJ, Lawson SL, Maurice S, et al. 2002. Global distribution of neutrons from Mars: Results from Mars Odyssey. Science 297: 75-78.

Kanavarioti A, Mancinelli RL. 1990. Could organic matter have been preserved on Mars for 3.5 billion years? Icarus 84: 196-202.

Klein HP. 1999. Did Viking discover life on Mars? Origins of Life Evol Biosph 29: 1573-0875.

Levin GV. 2007. Possible evidence for panspermia: The labelled release experiment. Int J Astrobiol 6: 95-108.

Levin GV, Straat PA. 1981. A search for a nonbiological explanation of the Viking Labeled Release life detection experiment. Icarus 45: 494-516.

Lehninger AL. 1975. Biochemistry. Worth, New York.

Malin MC, Carr MH. 1999. Groundwater formation on Martian valleys. Nature 397: 589-591.
McKay CP. 2004. What is life-and how do we search for it on other worlds? PLoS Biol 2: 1260-1263.

McSween HY Jr. 1984. SNC Meteorites; are they Martian rocks? Geology 12: 3-6.

Navarro-Gonzalez R, Navarro KF, de la Rosa J, Iniguez E, Molina P, Miranda LD, Morales P, Cienfuego E, Coll P, Raulin F, et al. 2006. The limitations on organic detection in Mars-like soils by thermal volatilization-gas chromatography-MS and their implications for the Viking results. Proc Nat Acad Sci 103: 16089-16094.

Navarro-Gonzalez R, Rainey FA, Molina P, Bagaley DR, Hollen BJ, de la Rosa J, Small AM, Quinn RC, Grunthaner FJ, Ceceres L, et al. 2003. Mars-like soils in the Atacama Desert, Chile and the dry limit of microbial life. Science 302: 1018-1021.

Schidlowski M. 1988. A 3,800-million-year isotopic record of life from carbon in sedimentary rocks. Nature 333: 313-318.

Smith HD, McKay CP. 2005. Drilling in ancient permafrost on Mars for evidence of a second genesis of life. Planet Space Sci 53: 1302-1308.

Squyres SW, Carr MH. 1986. Geomorphic evidence for the distribution of ground ice on Mars. Science 231: 249-252.

Tice MM, Lowe DR. 2004. Photosynthetic microbial mats in the 3416-Myr-old ocean. Nature 431: 549-552.

Vreeland RH, Rosenzweig WD, Powers DW. 2000. Isolation of a 250 million year old bacterium from primary salt crystals. Nature 408: 897-900.

Weiss BP, Kirschvink JL, Baudenbacher FJ, Vali H, Peters NT, Macdonald FA, Wikswo JP. 2000. A low temperature transfer of ALH84001 from Mars to Earth. Science 290: 791-795.

Willerslev E, Cooper A. 2005. Ancient DNA. Proc R Soc B 272: $3-16$. 


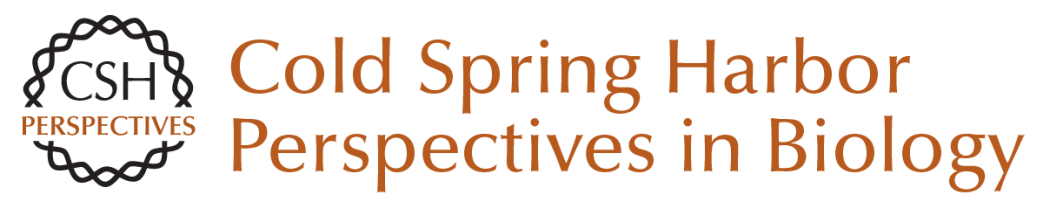

\section{An Origin of Life on Mars}

Christopher P. McKay

Cold Spring Harb Perspect Biol 2010; doi: 10.1101/cshperspect.a003509 originally published online March 3, 2010

\section{Subject Collection The Origins of Life}

\section{Constructing Partial Models of Cells} Norikazu Ichihashi, Tomoaki Matsuura, Hiroshi Kita, et al.

Ribonucleotides John D. Sutherland

Deep Phylogeny--How a Tree Can Help

Characterize Early Life on Earth Eric A. Gaucher, James T. Kratzer and Ryan N. Randall

Cosmic Carbon Chemistry: From the Interstellar Medium to the Early Earth Pascale Ehrenfreund and Jan Cami

\section{Origin and Evolution of the Ribosome} George E. Fox

\section{Planetary Organic Chemistry and the Origins of Biomolecules} Steven A. Benner, Hyo-Joong Kim, Myung-Jung Kim, et al.

Mineral Surfaces, Geochemical Complexities, and the Origins of Life Robert M. Hazen and Dimitri A. Sverjensky

Historical Development of Origins Research Antonio Lazcano
The Hadean-Archaean Environment Norman H. Sleep

An Origin of Life on Mars Christopher P. McKay

Primitive Genetic Polymers Aaron E. Engelhart and Nicholas V. Hud

\section{Membrane Transport in Primitive Cells Sheref S. Mansy}

The Origins of Cellular Life Jason P. Schrum, Ting F. Zhu and Jack W. Szostak

From Self-Assembled Vesicles to Protocells Irene A. Chen and Peter Walde

The Origin of Biological Homochirality Donna G. Blackmond

Earth's Earliest Atmospheres Kevin Zahnle, Laura Schaefer and Bruce Fegley

For additional articles in this collection, see http://cshperspectives.cshlp.org/cgi/collection/

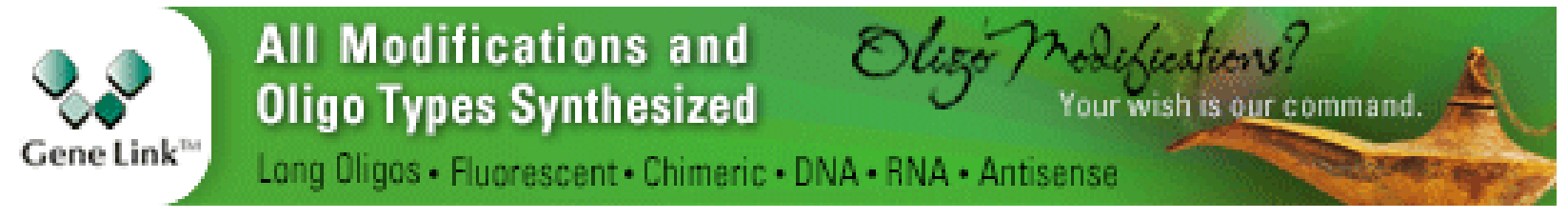

